\title{
O futuro da ANPHLAC: possibilidades e desafios ${ }^{1}$
}

Kátia Gerab Baggio*

No dia 15 de janeiro de 2013, comemoramos os 20 anos de existência da ANPHLAC. Os colegas que participaram desse processo recordam-se que o primeiro congresso na área de História da América, no Brasil, ocorreu em João Pessoa, na Universidade Federal da Paraíba, em 1984. Nesse evento, conforme Philomena Gebran, um pequeno - mas extremamente importante - grupo de professores começou a desenvolver a ideia da criação de uma associação de pesquisadores de História LatinoAmericana no Brasil. Entre eles, Anna Maria Martinez Corrêa, Heloísa Reichel, Manoel Lelo Bellotto, Maria Ligia Prado, Philomena Gebran e Silvia Petersen (GEBRAN, 2001, p.3). Daí brotou o projeto que foi concretizado na cidade de Mariana, nas dependências da Universidade Federal de Ouro Preto (UFOP): a fundação da Associação Nacional de Pesquisadores de História Latino-Americana e Caribenha, a ANPHLAC. ${ }^{2}$ Como se sabe, na assembleia realizada durante o V Encontro, em 2002, em Belo Horizonte, aprovou-se a ampliação da área de interesse da Associação para todo o continente americano, embora se mantendo o princípio de que os trabalhos voltados exclusivamente para a História do Brasil, sem vinculações com outros países do continente, não teriam a acolhida da Associação em suas publicações e eventos, considerando-se que o objetivo da instituição é exatamente estimular o ensino e a pesquisa em História das Américas, além do Brasil. A Associação manteve sua sigla, mas alterou seu nome para Associação Nacional de Pesquisadores e Professores de História das Américas.

Os demais artigos que compõem esse dossiê refletiram sobre a trajetória da Associação e da área de História das Américas no Brasil, nas últimas décadas, ao avaliarem os Encontros bienais, a Revista Eletrônica da ANPHLAC, o crescimento da pesquisa e das publicações na área, o acesso às fontes documentais, o potencial da

\footnotetext{
${ }^{1}$ Agradeço aos organizadores do Dossiê pelo convite para escrever esse artigo e aproveito para manifestar a minha satisfação e grande alegria por ter participado da história da ANPHLAC, de sua construção e consolidação, junto com tantos colegas e amigos da área de História das Américas.

* Professora Associada do Departamento de História da Universidade Federal de Minas Gerais (UFMG). E-mail: kgbaggio@ufmg.br

2 Ver, também, a entrevista de Maria Ligia Coelho Prado, concedida a Mary Junqueira e Vitória Rodrigues e Silva (JUNQUEIRA \& RODRIGUES e SILVA, 2004, p.65-79).
} 
Internet, o lugar da História das Américas nas diversas regiões e estados do Brasil, os intercâmbios com pesquisadores de outros países etc. Coube a mim uma tarefa desafiadora, mas muito estimulante. Refletir sobre as possibilidades de atuação da ANPHLAC e os desafios que se apresentam para a Associação no futuro.

Pensar sobre o futuro, como todos os historiadores sabem, implica em retomar o passado. Entretanto, tenho a intenção de, neste breve texto, não ceder demasiadamente às tentações que o ofício de historiadora me impõe, embora não possa me furtar a fazer várias considerações sobre os caminhos percorridos pela área de História das Américas nos últimos 30 anos, ou seja, desde o período da chamada "abertura política", nos inícios dos anos 1980. Se nessa época a produção historiográfica sobre as Américas no Brasil era praticamente inexistente, uma década depois, a situação começava a mudar. E a fundação da ANPHLAC foi uma iniciativa que revela a presença, nas universidades brasileiras de inícios dos anos 1990, de um número crescente e cada vez mais atuante de professores e pesquisadores da área preocupados com a necessidade de fortalecê-la. Para tanto, o Documento de Mariana explicitava os objetivos da ANPHLAC: o estímulo à formação de especialistas e ao intercâmbio entre os pesquisadores, com a troca de experiências e material de pesquisa. $^{3}$

Ao pensar sobre o futuro da ANPHLAC, busquei avaliar algumas características da pesquisa e do ensino na área de História das Américas e os desafios que considero mais relevantes e prementes. A seguir, busco fazer uma síntese desses desafios e, ao mesmo tempo, uma sinalização para as possibilidades que a situação atual da educação brasileira e as novas tecnologias proporcionam. Ao refletir sobre os desafios e possibilidades da ANPHLAC, foi inevitável voltar a questões que já tinham sido objeto de reflexão por parte de meus colegas que colaboraram com o dossiê. Mas ressalto que escrevi este texto sem possibilidades de ler, previamente, os artigos de meus colegas já que estavam sendo produzidos - e que, assim sendo, fico na esperança de que sejam complementares.

\section{Expansão das pesquisas em História das Américas pelo território brasileiro}

A partir de fins da década de 1980 e inícios dos anos 90, começou a ocorrer um crescimento muito significativo da produção na área de História das Américas,

\footnotetext{
${ }^{3}$ Ver ANPHLAC. Documento de Mariana. http://www.anphlac.org/historico.asp 
particularmente nos estados de São Paulo, Rio Grande do Sul, Rio de Janeiro e Distrito Federal. Na última década, essa produção ampliou-se de maneira muito significativa, inclusive com sua expansão para outros estados e regiões do país. Das 169 Teses de Doutorado em História das Américas, defendidas no Brasil entre 1987 e 2011 _ segundo levantamento realizado por Luiz Fernando Silva Prado (2012) - , apenas 41 foram concluídas até $2000 .{ }^{4}$ Ou seja, mais de $75 \%$ desses trabalhos foram defendidos nos primeiros 11 anos do atual século, sem contar as Dissertações de Mestrado. ${ }^{5}$ Entretanto, a quase totalidade das Teses na área defendidas até 2011, 162, concentrou-se em Programas de Pós-Graduação dos estados de São Paulo (74, sendo 61 na USP), Rio Grande do Sul (34, sendo 20 na PUC-RS), Rio de Janeiro (28, sendo 22 na UFF) e Distrito Federal (26, todas na UnB). A disseminação das pesquisas para outros estados e regiões do país é recente, tendo se iniciado na última década, com as defesas das primeiras Dissertações e Teses na área, orientadas, principalmente, por professores que fizeram Doutorado nas universidades que iniciaram as pesquisas em estudos americanos. No Espírito Santo, Goiás, Minas Gerais e Paraná, por exemplo, a produção cresceu nos últimos anos, mas, em outros estados do Centro-Oeste e nas regiões Norte e Nordeste, a pesquisa na área está apenas começando, com o ingresso recente de pesquisadores da área em universidades dessas regiões, particularmente nas instituições públicas.

Outro processo que tem estimulado a pesquisa está relacionado à expansão do sistema de Pós-Graduação. Em reunião com coordenadores de Pós-Graduação em História, em 2011, a CAPES manifestou que a intenção do MEC era a criação de pelo menos um curso de Mestrado, de diversas áreas do conhecimento, incluindo a História, em todos os estados da União. Essa política promoveu uma evidente expansão no

\footnotetext{
${ }^{4}$ Como o próprio autor esclarece, o levantamento foi realizado a partir dos dados encontrados nas páginas eletrônicas dos Programas de Pós-Graduação em História brasileiros, com cursos de Doutorado. Assim sendo, ainda que exaustivo, pode estar incompleto, além de não incluir teses de caráter histórico que tenham sido defendidas em Programas de áreas afins (PRADO, 2012, p.140-170).

${ }^{5}$ Segundo levantamento realizado por José Luis Bendicho Beired, das Teses e Dissertações defendidas na área de História das Américas, em instituições do estado de São Paulo com Programas de Pós-Graduação em História (USP, Unicamp, UNESP e PUC-SP), entre 1942 e 2004, dos 180 trabalhos, 61 foram concluídos nos últimos 5 anos do levantamento (2000-2004), ou seja, um terço (BEIRED, 2005, p.44, Gráfico 5). Ressalte-se que as diferenças numéricas entre os levantamentos feitos por Beired e Silva Prado, para o caso de São Paulo, devem-se ao fato de que Beired incluiu Dissertações de Mestrado, Teses de Doutorado, Teses de Livre-Docência e as antigas Teses de Cátedra, entre 1942 e 2004, enquanto Prado selecionou apenas as Teses de Doutorado, entre 1987 e 2011. Além disso, Beired incluiu Teses e Dissertações da área de História defendidas no PROLAM/USP, o Programa de Pós-Graduação Interunidades em Integração da América Latina (BEIRED, 2005; PRADO, 2012).
} 
sistema, sem contar a interiorização, política também adotada pelo MEC. Na área de História, existem hoje 64 Programas de Pós-Graduação, sendo 31 com Mestrado e Doutorado - mais antigos e consolidados -, 30 com Mestrado e 3 com Mestrados Profissionais (fonte: CAPES). ${ }^{6}$ Apesar de muitos desses Programas ainda estarem em fase de consolidação, com vários problemas e dificuldades a serem superados, essa expansão significou a criação de um novo estímulo à pesquisa na área de História em estados e regiões do país em que, até então, era apenas incipiente ou mesmo inexistente. Com o ingresso, nessas instituições, de professores que pesquisam História das Américas, a área tem evidentes condições para crescer. No Norte e Nordeste, onde praticamente não havia pesquisa na área, abre-se a possibilidade do surgimento de novos temas ou de novas perspectivas sobre temas já estudados. Por exemplo, no caso das pesquisas sobre fronteiras com os países vizinhos - que abordam diferentes aspectos: econômicos, sociais, culturais ou geopolíticos -, sabe-se que existe uma produção importante no Sul do Brasil, mas a boa nova é que pesquisas sobre o tema começaram a ser realizadas no Norte e Centro-Oeste, envolvendo as fronteiras, migrações e conexões na região amazônica, como é possível observar, por exemplo, em mesa-redonda realizada no X Encontro Internacional da ANPHLAC (ANPHLAC, 2012, Mesa Redonda 29, p. 13). Essas pesquisas envolvem não só as conexões com os vizinhos sul-americanos, como também possíveis conexões com o Caribe insular.

Vale destacar que a presença de pesquisadores em História das Américas em diversas regiões e estados do Brasil já é uma realidade, ainda que essa difusão do ensino e pesquisa na área necessite se expandir ainda mais. Ao examinar as filiações institucionais dos pesquisadores que apresentaram trabalhos no último Encontro da ANPHLAC, em julho de 2012, em São Paulo, encontramos colegas vinculados a instituições de estados em que não havia — ou havia poucos — especialistas na área, como Amapá, Amazonas, Roraima e Tocantins, na região Norte; Mato Grosso do Sul, no Centro-Oeste, ou atuando em campi situados no interior de estados como Bahia, Minas Gerais, Paraná, Rio Grande do Sul etc., em número crescente. Se essa já era uma realidade do interior de São Paulo, cada vez mais se manifesta no interior de outros estados, junto com o processo de ampliação e interiorização do sistema público de

\footnotetext{
${ }^{6}$ Dos três Programas com Mestrados Profissionais, dois são voltados para o Ensino de História, na Universidade Federal do Rio Grande (FURG) e Universidade de Caxias do Sul (UCS), ambas no Rio Grande do Sul, e um é dedicado às áreas de Bens Culturais e Projetos Sociais, da FGV do Rio de Janeiro.
} 
ensino superior. Esse cenário é resultado de um fenômeno importante dos últimos anos: jovens doutores e mestres, formados nos melhores Programas de Pós-Graduação do país, estão começando suas carreiras em instituições universitárias de diversas regiões, contribuindo para a ampliação e expansão do ensino e pesquisa, inclusive na área de História das Américas.

Do Nordeste, entretanto, apenas a Bahia (capital e interior) teve representantes entre os pesquisadores inscritos no último Encontro da ANPHLAC. Uma avaliação preliminar sugere que estados do Sul, Centro-Oeste e Norte, mais próximos das fronteiras com os vizinhos hispano-americanos, têm atraído mais pesquisadores da área do que os estados do Nordeste. Esse é um desafio importante: além de ampliar sua presença nas regiões Norte e Centro-Oeste, é necessária a inserção da área nas universidades nordestinas.

\section{Diversificação das áreas de pesquisa em História das Américas}

Em relação à produção de pesquisa na área, não há dúvida de que a História Política (particularmente, a partir dos pressupostos da chamada "nova história política") e a História Cultural — assim como a história político-cultural —, em suas diversas manifestações, têm hoje um lugar preponderante na historiografia, não só na área de estudos americanos, como na produção historiográfica de um modo geral, e não apenas no Brasil. Esse predomínio está relacionado com as transformações que a historiografia vivenciou nas últimas décadas, tanto em razão do declínio da historiografia tradicional, como da crise dos pressupostos teóricos marxistas - ainda que tenha havido, nos anos 80 e 90, um diálogo muito intenso com a produção marxista britânica, em especial, autores como Eric Hobsbawm, E. P. Thompson e Christopher Hill —, além da presença crescente de novos referenciais, principalmente os da Nouvelle Histoire. Até o início dos anos 80, temas relacionados à economia, particularmente ao comércio colonial no mundo ibérico — com a adoção de métodos quantitativos —, foram claramente preponderantes, mas declinaram fortemente nas últimas três décadas (BEIRED, 2005, p.43-44; PRADO, 2012, p.166). Nesse sentido, penso que seria desejável, no presente momento, um maior incremento à História Econômica - incluindo, evidentemente, os temas relacionados à integração, como o Mercosul etc. - e às várias dimensões da História Social, ainda que, como se sabe, os rumos da produção intelectual e acadêmica 
obedeçam a uma série de fatores, inclusive às linhas de pesquisa dos Programas de PósGraduação e dos professores orientadores, que estão relacionadas, evidentemente, aos rumos da historiografia, no Brasil e no exterior. E há outros campos de pesquisa, na área de História das Américas, que têm muito espaço para crescer, como História das Ciências, História das Religiões, História das Comunicações e Mídias, História das Artes, História da Educação, História do Ensino de História da América etc.

\section{Fortalecimento da pesquisa sobre períodos, regiões e países ainda pouco estudados no Brasil}

Também é um desafio importante a ampliação dos estudos em História da América Antiga (ou Pré-Hispânica) e Colonial. Como mostra Luiz Fernando Silva Prado, das 169 Teses de Doutorado na área, defendidas entre 1987 e 2011, apenas 7 foram dedicadas ao período pré-hispânico. Em América Colonial, a produção também está muito aquém do desejável: 19 teses, $11 \%$ do total. As teses defendidas sobre o século XIX totalizaram 43 (26\%) e sobre o século XX, 100 teses, ou 59\% do total. Ou seja, quase $60 \%$ das teses defendidas a partir de 1987 dedicaram-se ao século XX, em contraste com o predomínio dos estudos sobre o período colonial, até inícios da década de 1980 (PRADO, 2012, p.165). As possibilidades para essa ampliação estão relacionadas, evidentemente, ao aumento paulatino de orientadores de pesquisas sobre os períodos pré-hispânico e colonial, como já aconteceu no caso dos estudos sobre os séculos XIX e XX.

Da mesma maneira, é desafiadora a necessidade de ampliar as pesquisas, no Brasil, sobre regiões e países das Américas ainda muito pouco estudados. Os levantamentos realizados por José Luis Beired, no período 1942 a 2004 — no caso das Teses e Dissertações defendidas em universidades do estado de São Paulo —, e por Luiz Fernando Silva Prado, de 1987 a 2011, em todo o país, demonstram que os países mais estudados pelos brasileiros são Argentina, México, Uruguai, Cuba, Estados Unidos, Paraguai, Chile e Peru. ${ }^{7}$ Ressalte-se que, nos dois levantamentos, o Brasil aparece em primeiro lugar, em trabalhos comparativos ou que estabelecem conexões

\footnotetext{
${ }^{7}$ No levantamento de Silva Prado, a ordem, decrescente em relação ao número de trabalhos por países, é: Argentina, México, Uruguai, Cuba, Estados Unidos, Paraguai, Chile, Peru, Venezuela, Bolívia, Colômbia, Haiti e Jamaica (Chile, Peru, Venezuela e Bolívia foram abordados em 4 trabalhos cada país). Já no levantamento de Beired, a ordem se altera: Argentina, México, Estados Unidos, Peru, Paraguai, Cuba, Chile, Uruguai, Bolívia, Colômbia, Porto Rico, Panamá e Venezuela.
} 
entre o Brasil e outros países. Ou ainda, trabalhos que analisam o Brasil no contexto mais amplo da América do Sul, América Latina ou do continente como um todo. Também há trabalhos sobre o Mercosul, assim como sobre os Impérios Ibéricos na América e sobre a Espanha vinculada à América. De todos os países da América Hispânica, a Argentina é o mais pesquisado pelos brasileiros, como também nos trabalhos comparativos com o Brasil. Há regiões e países ainda não estudados no Brasil, na perspectiva histórica, ou que foram objeto de pouquíssimos trabalhos. Esse é o caso dos países centro-americanos e antilhanos. No caso das Antilhas - tanto das ilhas de colonização espanhola, como de colonização inglesa, francesa, norte-americana ou holandesa -, o único país que foi objeto de um número expressivo de pesquisas é Cuba. No que se refere aos países da América Central continental, a produção é muito reduzida. Faltam pesquisas, também, sobre a Venezuela, Colômbia, Equador e Bolívia, países ainda muito pouco estudados no Brasil. Sobre o Canadá e as Guianas, não há produção, e mesmo sobre a História dos Estados Unidos, a produção ainda é reduzida. Evidentemente que, por razões históricas e geográficas — além da presença de uma historiografia mais numerosa e consolidada, em países como Estados Unidos, México ou Argentina -, alguns países vão continuar a exercer maior atração sobre os pesquisadores brasileiros. Entretanto, a diversificação dos objetos de estudo é mais do que desejável.

\section{Ampliação do intercâmbio com pesquisadores de instituições estrangeiras e} aumento da visibilidade da produção brasileira sobre História das Américas no exterior

Nos últimos Encontros da ANPHLAC, a presença de colegas de outros países tem crescido. No X Encontro, participaram, como conferencistas ou em mesasredondas, pesquisadores vinculados a instituições de oito países, além do Brasil, mas essa presença ainda é reduzida. Além dos três conferencistas, convidados - Barbara Weinstein (NYU, EUA), Julio Pinto Vallejos (USACH, Chile) e Regina Crespo (UNAM, México) —, em um total de 206 pesquisadores inscritos, houve apenas onze vinculados a instituições estrangeiras - da Argentina, Colômbia, Espanha, Estados Unidos, França e Peru, sendo que, dentre eles, cinco de universidades argentinas (ANPHLAC, 2012). A Associação tem se tornado mais conhecida e possivelmente a 
presença de colegas do exterior aumentará nos próximos Encontros. É sabido o quão importante é o crescimento desse intercâmbio, principalmente com pesquisadores de instituições do próprio continente, mas também com americanistas de outros continentes.

A participação de pesquisadores brasileiros em eventos no exterior - nas Américas e na Europa, principalmente - tem crescido muito, particularmente na última década, em razão das facilidades de comunicação trazidas pela Internet e do aumento dos financiamentos - pelas agências de apoio à pesquisa, Programas de Pós-Graduação e universidades. Acredito que esse crescimento, em razão do incremento nas trocas intelectuais, tenha como um dos resultados o aumento da presença de colegas de instituições estrangeiras no Brasil, o que é muito importante para os alunos de Graduação e Pós-Graduação. De fato, isso já vem acontecendo em nossas instituições. A presença crescente de pesquisadores brasileiros no exterior também tem contribuído para uma maior visibilidade, em outros países, da produção realizada no Brasil, inclusive por meio do incremento de publicações, principalmente de artigos em revistas estrangeiras. Entretanto, ainda é uma inserção relativamente tímida, dado o volume e a qualidade da produção brasileira atual em História das Américas. Comparando-se, contudo, com períodos anteriores, esse espaço maior destinado à nossa produção é significativo. As diferenças entre as línguas ainda têm peso, mas, na América Hispânica e mesmo nos Estados Unidos, aos poucos, o português tem conquistado um espaço maior, principalmente nas universidades.

Também cresce o número de colegas estrangeiros - principalmente argentinos — que encaminham artigos para avaliação pela Revista Eletrônica da ANPHLAC, o que demonstra o aumento da visibilidade do periódico. Se até 2010 (número 9) havia, em geral, um artigo de colega estrangeiro publicado por número, nos últimos quatro números — que coincidem com a alteração da periodização de anual para semestral —, têm sido publicados de dois a três artigos remetidos do exterior.

\section{Aumento dos vínculos com o ensino fundamental e médio: um grande desafio}

$\mathrm{O}$ aumento dos vínculos entre a produção acadêmica e o ensino fundamental e médio sempre foi um dos maiores desafios das universidades e do sistema de ensino, de 
um modo geral. ${ }^{8}$ A ANPHLAC tem manifestado essa preocupação desde a sua fundação. Em razão desse objetivo, organizou, na sua página na Internet, materiais de apoio didático ao ensino de História das Américas. Esses materiais foram organizados em três grandes blocos — “América Pré-colonial/Indígena; América Colonial e América Independente" - e, em cada um desses blocos, uma lista de temas pertinentes ao período. A inclusão de materiais está sendo feita paulatinamente, em razão da disponibilidade dos professores, que fazem o trabalho de maneira voluntária, sem qualquer tipo de remuneração. Sendo assim, há materiais disponíveis em parte dos temas arrolados. Em cada tema, há uma apresentação, documentos e, a depender do assunto, cronologia, mapas, bibliografia, sugestões de filmes, links para acervos documentais ou bibliotecas virtuais etc. ${ }^{9}$

Atualmente, a partir dos Parâmetros Curriculares Nacionais (PCN), a maioria das coleções didáticas, tanto as voltadas para o ensino fundamental como para o ensino médio, abordam os conteúdos de História de forma integrada, em que a chamada "História Geral" é trabalhada de maneira concomitante e inter-relacionada (ou, muitas vezes, apenas intercalada) com a História do Brasil, das Américas e, em parte dos casos, com conteúdos da História da África (que foi incluída por lei nos programas de História) e da Ásia. Em número bem menor, há coleções didáticas que adotam a perspectiva temática, em que a abordagem dos conteúdos se dá através de eixos temáticos, em múltiplos contextos espaciais e temporais, sem, contudo, ignorar a cronologia (MEC, 2010; MEC, 2011).

Sendo assim, não há, no ensino fundamental e médio, espaço para a História das Américas em uma única série, por exemplo, como já ocorreu anteriormente, em outros contextos políticos e educativos (RODRIGUES e SILVA, 2004). As perspectivas integrada ou temática da História, presentes nos atuais manuais didáticos, buscam superar, evidentemente, a visão tradicional de histórias estanques: "Geral" (eurocêntrica), do Brasil e da América, o que constitui, a meu ver, um avanço pedagógico. Entretanto, ao examinar os conteúdos das coleções didáticas, verifica-se que poucos conteúdos de História das Américas são incorporados: de um modo geral, a conquista e colonização espanhola, as independências, a Guerra Civil norte-americana,

\footnotetext{
${ }^{8}$ Sobre a inserção da História das Américas no ensino fundamental e médio, no Brasil, ver RODRIGUES e SILVA (2004), DIAS (1997) e BITTENCOURT (1996).

${ }^{9}$ Ver http://www.anphlac.org/apoio.asp
} 
os chamados populismos, as ditaduras na América Latina, além de alguns poucos temas além desses, dependendo da coleção — em alguns casos, aparecem as sociedades indígenas pré-coloniais, a América Latina no século XIX, as Repúblicas oligárquicas latino-americanas ou a Revolução Cubana (MEC, 2010; MEC, 2011).

Considero que caberia à ANPHLAC estimular os professores e autores de manuais didáticos a ampliar a presença de conteúdos de História das Américas, articulados com a História do Brasil, Europa e África, conforme as perspectivas atuais, de história integrada ou história temática. Para tanto, os materiais que constam na página da Associação na Internet seriam muito úteis.

\section{Publicações}

Nos últimos 20 anos, tem sido crescente o número de trabalhos publicados, no Brasil, na área de História das Américas - muitos deles, de excelente qualidade. Parte significativa desses livros tem origem em Teses ou Dissertações e foram publicados, em grande medida, com apoio das agências de fomento — principalmente as estaduais ou dos Programas de Pós-Graduação em História. Também são várias as coletâneas, sendo que grande parte delas contém textos originalmente apresentados em eventos acadêmicos sobre temáticas americanistas. Da mesma forma, houve crescimento no número de dossiês sobre História das Américas nas revistas acadêmicas de História, em vários estados do país. O número de títulos publicados, no Brasil, de autores hispanoamericanos também aumentou, embora de forma muito lenta e insuficiente, e, entre esses autores, a quantidade de historiadores é muito pequena. Isso é algo que ainda precisa de forte incremento, mas depende, também, do interesse das editoras. No caso da História dos Estados Unidos, a quantidade de obras historiográficas, publicadas em português, também é ínfima, o que não deixa de surpreender.

Hoje, entretanto, temos à disposição, pela Internet, uma grande quantidade de periódicos acadêmicos de diferentes países do continente, além dos livros eletrônicos e aqueles disponibilizados na rede mundial, conforme comentaremos a seguir. ${ }^{10}$

\footnotetext{
${ }^{10}$ Acerca das publicações de livros impressos sobre História e Literatura Latino-Americana, no Brasil, ver SOARES \& PINTO, 2004. 


\section{Abertura de novas possibilidades de pesquisa na Internet: fontes, bibliografia, divulgação e ensino}

Há 20 anos, em 1993, quando a ANPHLAC foi fundada, os computadores pessoais (na época, apenas computadores de mesa, os desktops) estavam começando a se difundir no Brasil. A Internet, por sua vez, só começou a se difundir no país a partir de fins dos anos 90 e, de forma mais intensa, na década passada.

O processo de pesquisa passou por transformações profundas com a expansão da rede mundial, facilitando o acesso a fontes e bibliografia em uma proporção inimaginável no início da década de 1990, pelo menos para a imensa maioria das pessoas, insuficientemente informadas sobre os possíveis avanços da computação. A quantidade cada vez maior de fontes documentais, periódicos e bibliografia online, dos mais diversos países, abriu possibilidades impressionantes de pesquisa. Citarei apenas alguns exemplos.

Na América Hispânica, uma das iniciativas importantes vem da Venezuela, que está tornando disponível, gratuitamente, os volumes da Biblioteca Ayacucho, criada em 1974. Concebida pelo crítico uruguaio Ángel Rama e pelo poeta venezuelano José Ramón Medina, as coleções da Biblioteca Ayacucho abrigam autores e textos fundamentais do pensamento e da literatura latino-americanos. ${ }^{11}$

Também é muito útil a página América Latina Portal Europeo, que é fruto da cooperação entre a REDIAL — Red Europea de Información y Documentación sobre América Latina - e o CEISAL - Consejo Europeo de Investigaciones Sociales de América Latina. A página contém periódicos (com acesso gratuito aos artigos); listas de pesquisadores, instituições, acervos, cursos de Pós-Graduação e teses defendidas em instituições europeias desde 1980; Biblioteca Virtual etc. Ou seja, através da página, é possível ter referências muito organizadas e consistentes acerca da produção de instituições acadêmicas europeias sobre a América Latina, em várias áreas das Ciências Humanas e Sociais. São 253 revistas especializadas em estudos latino-americanos, de 19 países, além de 3 revistas ligadas a instituições transnacionais. A Espanha é a recordista em número de revistas, com 116 periódicos, ou seja, 46\% do total. Ressaltese que o maior número de pesquisadores, 588, é de historiadores e que o segundo país

\footnotetext{
${ }^{11}$ Ver http://www.bibliotecayacucho.gob.ve 
mais pesquisado, depois do México, é o Brasil, seguido da Argentina. O portal permite realizar buscas por períodos históricos, países, regiões ou palavras-chave. ${ }^{12}$

Para os pesquisadores de História dos Estados Unidos, o acesso aos acervos norte-americanos, que ampliam constantemente a quantidade de documentos na rede, é fundamental. Um dos projetos liderados pelo historiador Robert Darnton, atual diretor da rede de bibliotecas da Universidade de Harvard, é o de digitalizar e tornar acessível gratuitamente os livros e documentos da instituição. Esse projeto é extremamente promissor, pois poderá intensificar de maneira impressionante o potencial de pesquisas, inclusive sobre História Latino-Americana. Segundo Darnton, o acervo de "17 milhões de volumes em 350 línguas" de Harvard deve ser acessível, como um "depósito internacional de conhecimento". E complementa:

\footnotetext{
O futuro é o acesso aberto. Abrir os tesouros intelectuais guardados nas nossas grandes bibliotecas de pesquisa, como a de Harvard, para o mundo. Eu recebi a incumbência de criar a Biblioteca Pública Digital da América, e há dois anos estamos trabalhando para criar um novo tipo de biblioteca. Vamos pegar coleções digitais de todas as grandes bibliotecas do país e usálas como base de uma grande coleção de livros, manuscritos, filmes, gravações e canções que ficarão disponíveis de graça para todo mundo no mundo. Vamos estrear em abril do ano que vem. Será uma versão preliminar, mas vai crescer até um dia, eu acho, superar a Biblioteca do Congresso, a maior do mundo (DARNTON, 29/05/2012).
}

Um dos maiores desafios para realizar o projeto, segundo Darnton, está relacionado à propriedade intelectual, aos direitos de proteção das obras (copyright) e à lei norte-americana, que restringe o acesso livre até 70 anos após a morte do autor, assim como na legislação brasileira e da maioria dos países. Entretanto, o historiador norte-americano afirma acreditar que, juridicamente, haja maneiras de defender o "uso justo" das obras. A ideia é disponibilizar esse conteúdo paulatinamente a partir de abril de 2013 (DARNTON, 29/05/2012).

Tomei apenas três exemplos de iniciativas que considero fundamentais, mas que, sem dúvida, se somarão a outras, possibilitando uma ampliação e aprofundamento sem precedentes das pesquisas e, no caso que nos ocupa nesse artigo, dos estudos sobre a Histórias das Américas no Brasil. Da mesma forma, as possibilidades criadas para a

\footnotetext{
${ }^{12}$ Ver http://www.red-redial.net

Revista Eletrônica da ANPHLAC, Dossiê Especial, p. 124-138, jan./jun. 2013. http://revista.anphlac.org.br/index.php/revista
} 
utilização de todos esses acervos — os que já estão disponíveis e os que começarão a estar, brevemente —, em todos os níveis de ensino, é incalculável.

\section{Considerações finais: a busca pela superação das histórias nacionais}

Não há dúvidas de que, na área de estudos americanistas, há uma tendência concreta de se superar as histórias nacionais, herdeiras da tradição historiográfica do século XIX. É cada vez maior a presença, no Brasil e em outros países, de trabalhos que adotam as perspectivas da História Comparada, Histórias Conectadas ou História Transnacional. Nas teses produzidas no Brasil, nos últimos 20 anos, pode-se observar o crescimento destas tendências, ainda que de forma insuficiente. Como observaram Maria Ligia Prado (2005) e Ricardo López \& Barbara Weinstein (2012), a adoção dessas perspectivas teórico-metodológicas são promissoras, no sentido de provocar novas reflexões a partir de novos problemas. E a ANPHLAC tem muito a contribuir nesse sentido, ao estimular o intercâmbio e o debate fértil entre pesquisadores que trabalham com diferentes temas, países e regiões das Américas.

\section{Referências bibliográficas}

ANPHLAC. Documento de Mariana. Disponível em: http://www.anphlac.org/historico.asp

ANPHLAC. X Encontro Internacional da ANPHLAC. Programação e Resumos. São Paulo: ANPHLAC, 2012.

BEIRED, José Luis Bendicho. A pesquisa de História da América: sua trajetória nas universidades paulistas (1942-2004). In: Revista de História, São Paulo, USP, n. 153, p. 35-52, 20.-2005. Disponível em: http://revhistoria.usp.br

BIBLIOTECA AYACUCHO. Disponível em: http://www.bibliotecayacucho.gob.ve BITTENCOURT, Circe Maria F. O percurso acidentado do ensino de História da América. In: BITTENCOURT, C. \& IOKOI, Z. (Coord.). Educação na América Latina. Rio de Janeiro: Expressão e Cultura; São Paulo: Edusp, 1996, p. 203-218 (Col. “América 500 Anos”, v. 3). 
DARNTON, Robert. Entrevista. Folha de S. Paulo, 29/05/2012. Disponível em: http://www1.folha.uol.com.br/ilustrada/1096772-o-eurocentrismo-morreu-dizhistoriador-robert-darnton.shtml

DARNTON, Robert. Entrevista. Roda Viva. TV Cultura, 21/09/2012. Disponível em: http://tvcultura.cmais.com.br/rodaviva/roda-viva-recebe-robert-darnton

DIAS, Maria de Fátima Sabino. A "invenção da América” na cultura escolar no Brasil. Campinas: Unicamp, 1997 (Tese de Doutorado em Educação).

GEBRAN, Philomena. Histórico da ANPHLAC. In: Revista Eletrônica da ANPHLAC, São Paulo, n. 1, p. 3-6, 2001. Disponível em: http://www.anphlac.org/revista/revista1/revista_anphlac_1.pdf

JUNQUEIRA, Mary \& RODRIGUES e SILVA, Vitória. Entrevista com Maria Ligia Coelho Prado. In: Diálogos, Maringá, UEM, v. 8, n. 2, p. 65-79, 2004.

LÓPEZ, A. Ricardo; WEINSTEIN, Barbara(ed.). Introduction. The Making of the Middle Class: Toward a Transnational History. Durham, N. C.: Duke University Press, 2012.

MEC. Guia de livros didáticos: PNLD 2011: História. Anos Finais do Ensino Fundamental. Brasília: MEC, Secretaria de Educação Básica, 2010. Disponível em: http://www.fnde.gov.br/programas/livro-didatico/guia-do-livro

MEC. Guia de livros didáticos: PNLD 2012: História. Ensino Médio. Brasília: MEC, Secretaria de Educação Básica, 2011. Disponível em:

http://www.fnde.gov.br/programas/livro-didatico/guia-do-livro

PRADO, Luiz Fernando Silva. Itinerários acadêmicos da História da América no Brasil. Goiânia: Kelps, 2012.

PRADO, Maria Ligia Coelho. À guisa de introdução: pesquisa sobre História da América Latina no Brasil. In: Revista Eletrônica da ANPHLAC, São Paulo, n. 1, p. 10-12, 2001. Disponível em:

http://www.anphlac.org/revista/revista1/revista_anphlac_1.pdf

PRADO, Maria Ligia Coelho. Repensando a História Comparada da América Latina. In: Revista de História, São Paulo, USP, n.153, $2^{\circ}$ semestre de 2005, p. 11-33. Disponível em: http://revhistoria.usp.br

REDIAL/CEISAL. América Latina Portal Europeo. Disponível em: http://www.redredial.net 
REICHEL, Heloisa J. A produção bibliográfica sobre História da América no Brasil, nas duas últimas décadas do século XX. In: Revista Eletrônica da ANPHLAC, S. Paulo, n.1, p. 7-9, 2001. Disponível em:

http://www.anphlac.org/revista/revista1/revista_anphlac_1.pdf

RODRIGUES e SILVA, Vitória. O ensino de História da América no Brasil. In: Diálogos, Maringá, UEM, v. 8, n. 2, 2004, p. 83-104.

SOARES, Gabriela Pellegrino; PINTO, Júlio Pimentel. A América Latina no universo das edições brasileiras. In: Diálogos, Maringá, UEM, v. 8, n. 2, 2004, p. 133-151. 